\title{
IL-10 regulation of lupus in the NZM2410 murine model
}

\author{
Kim RM Blenman ${ }^{1}$, Byian Duan ${ }^{1}$, Zhiwei Xu ${ }^{1}$, Suigui Wan ${ }^{1}$, Mark A Atkinson ${ }^{1}$, \\ Terence R Flotte ${ }^{2}$, Byron P Croker ${ }^{1,3}$ and Laurence Morel ${ }^{1}$ \\ ${ }^{1}$ Department of Pathology, Immunology, and Laboratory Medicine, University of Florida, Gainesville, FL, \\ USA; ${ }^{2}$ Department of Pediatrics, University of Florida, Gainesville, FL, USA and ${ }^{3}$ Pathology and Laboratory \\ Medicine Service, North Florida/South Georgia Veterans Health System, Gainesville, FL, USA
}

\begin{abstract}
Multiple studies have reported high levels of IL-10 in SLE patients and in murine models of lupus. IL-10 is a regulatory cytokine mainly produced by $B$ cells, which use this cytokine to support their proliferation, and by myeloid cells, which use IL-10 to reduce proinflammatory responses. IL-10 is also produced by a subset of $\mathrm{CD}^{+} \mathrm{T}$ regulatory cells. Various manipulations of IL-10 levels with repeated administrations of anti-IL-10 neutralizing antibodies, genetic ablation or injections of recombinant cytokine have shown contradictory results, which is likely to reflect the opposite effects of this cytokine on the two major effector arms of lupus pathologenesis, namely B cells and inflammation. We have investigated the role of IL-10 in a novel congenic model of lupus, B6.Sle1.Sle2.Sle3 (B6.TC), which consists of the three NZM2410-derived SLE susceptibility loci combined on a C57BL/ 6 background. We first investigated in this model the source of elevated IL-10 and shown that it results from a larger number of $\mathrm{CD4}^{+} \mathrm{T}$ cells producing the cytokine, and from a greatly increased B1-a cell pool, which is the main IL-10 producing compartment. We have then used AAV-mediated skeletal muscle gene delivery to overexpress IL-10 in young B6.TC mice and follow disease marker expression up to 7 months of age. We show here that continuous overexpression of low levels of IL-10 significantly delayed antinuclear auto-antibody production and decreased clinical nephritis. B cell phenotypes were largely unaffected, while T-cell activation was significantly reduced. This highlighted the pivotal role played by T-cell activation in this model, and suggested that this pathway could be effectively targeted for therapeutic interventions. These results also reinforce the notion that IL-10 exerts multiple functions and commend caution in equating high levels of IL-10 and increased pathogenesis in systemic autoimmunity.
\end{abstract}

Laboratory Investigation (2006) 86, 1136-1148. doi:10.1038/labinvest.3700468; published online 21 August 2006

Keywords: IL-10; lupus; inflammation; AAV; gene therapy

IL-10 is a pleiotropic cytokine that possesses both immunosuppressive and immunostimulatory properties. Its potentials of dampening inflammatory responses have generated a lot of interest in autoimmune research. ${ }^{1}$ Numerous studies have shown an increased IL-10 production by the peripheral blood B cells and monocytes from systemic lupus erythematosus (SLE) patients, and this increase correlated with disease activity. ${ }^{2}$ Increased IL-10 production in SLE patients may have a genetic basis, ${ }^{3,4}$ and a polymorphism in the IL-10 promoter has been associated with lupus susceptibility. ${ }^{5}$ Inhibition of IL-10 action through use of neutraliz-

Correspondence: Dr L Morel, PhD, Department of Pathology, Immunology, and Laboratory Medicine, University of Florida, Gainesville, FL 32601-0275, USA.

E-mail: morel@ufl.edu

Received 13 February 2006; revised and accepted 26 July 2006; published online 21 August 2006 ing antibodies results in decreased disease marker expression SLE patients. ${ }^{1}$ These results have been generally interpreted as intrinsically high levels of IL-10 contribute to lupus susceptibility and severity by promoting B-cell proliferation, and therefore the immunostimulation by this cytokine trumps over immunosuppression in lupus patients. Experimental studies using murine models have, however, uncovered a more complex situation.

High IL-10 levels have been described in all murine models of SLE. ${ }^{6}$ Moreover, continuous administration of anti-IL-10 antibody to NZB/W F1 mice significantly delayed the development of lupus, and this effect was attributed to an increased production of $\mathrm{TNF} \alpha_{0}{ }^{7}$ These results corroborated the hypothesis that increased IL-10 levels promote lupus pathogenesis. Genetic deficiency of IL-10 resulted, however, in significantly enhanced disease severity in the MRL/lpr model with increase in IFN $\gamma$ and IgG2a anti-dsDNA auto-antibody production, 
while administration of r-IL-10 reduced the expression of these disease markers. ${ }^{8}$ These contradictory results may be explained by the dual effects of IL-10, which stimulates B cells and auto-antibody production, but downregulates inflammatory T cells.

The purpose of this study was first to evaluate IL-10 production in the NZM2410-derived B6.Sle1.Sle2.Sle3 mouse model of SLE. NZM2410 is a recombinant inbred strain produced from NZB and NZW that develops a highly penetrant lupuslike disease in both males and females. ${ }^{9}$ We have shown that three major genetic loci, Sle1-3, are responsible for disease susceptibility. ${ }^{10}$ The triple congenic strain, B6.Sle1.Sle2.Sle3 or B6.TC, which expresses these three loci on a C57BL/6 (B6) background, also develops a highly penetrant lupus nephritis, although with a delayed onset as compared to NZM2410. ${ }^{11}$ The B6.TC strain represents a genetically simplified lupus model which shares $96 \%$ of its genome, including the MHC, with B6, which can therefore be used as a control strain. As its parental strain NZM2410, B6.TC mice produce large amounts of antinuclear auto-antibodies and their lymphocytes exhibit a high level of activation. Although an elevated IL-10 production is expected in B6.TC mice as in the other SLE models, we investigated which cellular compartment is responsible for this over production. B6.TC mice accumulate large amounts of B-1a cells, ${ }^{12}$ and this cellular compartment is the major producer of IL-10. ${ }^{13} \mathrm{IL}-10$ is however produced by other cells types, including $\mathrm{T}$ cells and dendritic cells, and there is evidence that regulation of IL-10 production differs between these cell types. ${ }^{14} \mathrm{~T}$ cells and dendritic cells show increased activation levels in lupus, which may affects their ability to produce IL-10.

The second part of this study addresses the effect of IL-10 overexpression on disease progression and biomarker expression in the B6.TC model. To overexpress IL-10 in vivo, we have used an AdenoAssociated Virus (AAV) vector. AAV is a $4.7 \mathrm{~kb}$ single-stranded DNA nonpathogenic defective human parvovirus that is utilized as a viral vector for gene therapy. In the absence of a helper virus, such as adenovirus, AAV integrates into the genome of mitotic and postmitotic cells of many different types in a variety of animal species, including mice. ${ }^{15}$ The cis elements are (ITRs). In AAV vectors, the transgene of interest is inserted in between the inverted terminal repeats (ITRs), which are required for replication, packaging, insertion into and release from the host chromosome. Continuous stable production of secreted cytokines can be achieved in vivo through recombinant $\mathrm{AAV}$-mediated skeletal muscle gene delivery. ${ }^{15-17}$ AAV-IL-10 has now been used successfully as an anti-inflammatory gene therapy in many models, including endotoximia, ${ }^{18}$ arthritis, ${ }^{19,20}$ atherosclerosis, ${ }^{21}$ experimental autoimmune orchitis, ${ }^{22}$ experimental autoimmune uveitis, ${ }^{23,24}$ chronic renal disease $^{25}$ and type 1 diabetes. ${ }^{26-29}$ Interestingly, it has been shown in this latter model that the protective effect of IL-10 overexpression was mediated through the induction and mobilization of $\mathrm{CD} 4{ }^{+} \mathrm{CD} 25^{+}$regulatory T cells $\left(T_{R}\right){ }^{30}$ These results indicated that in these largely inflammatory $\mathrm{T}_{\mathrm{H} 1}$ cell-mediated diseases, the immunosuppressive activity of IL-10 was dominant. In SLE, however, there is no clear cut $\mathrm{T}_{\mathrm{H} 1}$ vs $\mathrm{T}_{\mathrm{H} 2}$ imbalance, ${ }^{8,31}$ and both $\mathrm{B}$ cells and $\mathrm{T}$ cells play a necessary role in disease initiation and progression, making the role of IL-10 less predictable.

\section{Materials and methods}

\section{Mice}

The production of the B6.Sle1.Sle2.Sle3 (B6.TC) has been previously described. ${ }^{11}$ B6.TC and C57BL/6J (B6) mice were bred and maintained in specific pathogen free housing at the University of Florida and all experiments were conducted according to IACUC approved protocols. The entire study was conducted on females only, at the age indicated for each experiment, since females develop an earlier disease onset. ${ }^{11}$

\section{Cytokine Measurements}

B6. TC and B6 control mice were used at 7-8 months of age. Red blood cell depleted splenocytes were incubated at a concentration of $10^{6}$ cells $/ \mathrm{ml}$ with $2 \mu \mathrm{g} / \mathrm{ml}$ of anti-CD28 in anti-CD3 precoated plates (BD Pharmingen, San Diego, CA, USA) for 3 days. Total peritoneal cavity (perC) cells were washed out from the peritoneal cavity with 10\% FBS-PBS and then cultured with $1 \mu \mathrm{g} / \mathrm{ml}$ LPS (Sigma, St Louis, MO, USA) for 3 days. Bone-marrow-derived dendritic cells were produced with GM-CFS and IL-4 according to established protocols. ${ }^{32}$ IL-10 levels in the supernatants were measured with a OptEIA Mouse IL-10 ELISA kit (BD Pharmingen) according to manufacturer's instructions. For intracellular cytokine staining, spleen cells were incubated for $5 \mathrm{~h}$ in presence of leukocyte activation cocktail with Golgiplug (BD Pharmingen). After blocking, lineage surface markers were stained with anti-CD4 (RM45), B220-FITC (RA3-6B2), CD5-PE (53-7.3) and CD11c (HL3). Then cells were fixed and permeabilized in BD Cytofix/Cytoperm ${ }^{\mathrm{TM}}$ solution and intracellular cytokine was stained with anti-IL-10-PE (JES5-16E3). The stained cells were analyzed with a FACS Calibur cytometer (BD Biosciences, Mountain View, CA, USA). For the perC B-cell subset analysis, whole peritoneal lavages were incubated at $37^{\circ} \mathrm{C}$, $10 \% \mathrm{CO}_{2}$ for $2 \mathrm{~h}$ in $10 \mathrm{~cm}$ diameter cell culture dish to remove macrophages. Then cells were cultured with medium (RPMI 1640) only, $10 \mu \mathrm{g} / \mathrm{ml}$ of AffiniPure $\mathrm{F}\left(\mathrm{ab}^{\prime}\right)_{2}$ goat anti-mIgM (Jackson ImmunoResearch Laboratories, West Grove, PA, USA) or LPS ( $1 \mu \mathrm{g} / \mathrm{ml})$ for an additional 24 or $48 \mathrm{~h}$. Intracellular staining was performed as described 
above. B-1a and B-2 cells were gated as B220 $0^{\mathrm{lo}} \mathrm{CD} 5^{+}$ and $\mathrm{B} 220^{\text {hi }} \mathrm{CD}^{-}$, respectively. Serum IL-10, IFN $\gamma$ and $\mathrm{TNF} \alpha$ were measured with OptEIA Mouse ELISA kits on sera diluted 1:50.

\section{Treatment with IL-10 AAV}

The construction of the mouse IL-10 AAV serotype 1 vector has been previously described. ${ }^{26,30}$ Briefly, a murine IL-10 cDNA was cloned into the p43.2 plasmid with expression driven by a fused CMVchicken $\beta$-actin promoter with human 293 cells used as the primary hosts. Calcium phosphate-mediated cell transfection was used to introduce the plasmid DNA into the host cell. The rAAV1 vector plasmid p43.2 containing the mouse IL-10 gene was combined with helper plasmid pDG, which contained both the AAV genes (rep and cap) and the adenovirus genes. ${ }^{33}$ Recombinant AAV production, titer and infectivity determination were performed as previously described. ${ }^{33}$ Mice (6 weeks old) were injected in the caudal muscle of both hind legs with $10^{10} \mathrm{IU}$ of murine IL-10 AAV serotype 1 resuspended in $100 \mu \mathrm{l}$ PBS or PBS alone. Mice were bled and tested for proteinuria bi-monthly up to 26 weeks after transduction (about 8 months of age) when the experiment was terminated. Upon killing, tissues were harvested for histology, RNA extraction and flow cytometry.

\section{RT-PCR Assessment of IL-10 Expression}

Total RNA from caudal muscles was extracted with Clontech reagents (BD Clontech, Palo Alto, CA, USA) according to manufacturer's instructions. Nested one-step RT-PCR was performed as previously described 30 with Stratascript RT reagents (Stratagene, La Jolla, CA, USA). Each PCR round performed 40 cycles of amplification with an annealing temperature of $60^{\circ} \mathrm{C}$. Primer sequences were as follows: P1: AGTCGCTGCGACGCTGCCTT and P2: CTGCTCCACTGCCTTGCTCT amplifying a $586 \mathrm{bp}$ product; P3: GGCTCTGACTGACCGCGTTA and P4: GCAGCTCTAGGAGCATGGG amplifying a $232 \mathrm{bp}$ product.

\section{Antibody Measurement}

Total serum IgM and IgG isotypes and IgG autoantibody directed against dsDNA or chromatin were measured by ELISA. For total immunoglobulin measurement, plates were coated with an anti-kappa antibody (Southern Biotech), then blocked with 6\% BSA. Serum samples diluted 1:200000 and standard immunoglobulin serial dilutions were added. Secondary antibodies were alkaline phosphataseconjugated anti-IgG (Chemicon International, CA, USA), -IgG1, -IgG2a, -IgG2b, -IgG3 or -IgM (Southern Biotech, Birmingham, AL, USA). For anti-dsDNA and anti-chromatin IgG measurement, plates were coated with dsDNA (Sigma, St Louis, MO, USA) or total histone (Boeringher Mannheim, Germany) and dsDNA, respectively, and blocked with 6\% BSA. Serum samples diluted 1:100 and serial dilutions of an NZM2410 standard were added, and samples were exposed to anti-IgG alkaline phosphatase antibody (Chemicon, Temecula, CA, USA). Values were expressed as units with $100 \mathrm{U}$ corresponding to the value for the 1:100 dilution of the NZM2410 standard. The samples were visualized with pNPP substrate and optical densities were measured at $405 \mathrm{~nm}$ using a standard microtiter plate reader.

\section{Kidney Histology}

Proteinuria was determined semi-quantitatively with Albustix strips (Bayer, Elkhart, IN), using a 0-4 scale (0: negative, 1: $30 \mathrm{mg} / \mathrm{dl}, 2: 100 \mathrm{mg} / \mathrm{dl}, 3$ : $300 \mathrm{mg} / \mathrm{dl}$ and 4 : over $2000 \mathrm{mg} / \mathrm{dl}$ of urinary protein). The type and extent of glomerular lesions was evaluated on hematoxylin and eosin (H\&E) and periodic acid Schiff (PAS) stained section using a classification based on modifications of the WHO and RPS/ISN Classification of Glomerulonephritis in Systemic Lupus Erythematosus ${ }^{34,35}$ with a semiquantitative overlay as previously described. ${ }^{11}$ For immunofluorescence staining, kidney sections $(8 \mu \mathrm{m})$ were fixed in cold acetone and blocked with the Avidin-Biotin Blocking Set (Biomeda, Foster City, CA, USA), then 1\% normal rat serum in PBS. Sections were stained with 1:100 dilution of FITCconjugated anti-C3 (Cappel, Malvern, PA, USA) or anti-IgG (Southern Biotech, Birmingham, AL, USA).

\section{Flow Cytometry}

Single cell suspensions from bone marrow, spleen and peritoneal cavity were treated with FcR Block $(2.4 \mathrm{G} 2)$ and directly stained with monoclonal antibodies to mouse CD5 (53-7.3), B7.2 (GL1), B220 (RA3-6B2), CD19 (1D3), IL12R (C-20), CD24 (M169), CD43 (S7), CD43, IgDb (217-170), IgMb (LL/41), CD4 (RM4-5), CD8 (53-6.7), CD69 (H1.2F3), CD44 (1M7), CD62L (MEL-14), CD138 (281-2), CD23 (B3-B4), CD21 (7E9), CD25 (7D4) (all from Pharmingen) or IgG (Southern Biotech). Biotinylated antibodies were revealed with Streptavidin Quantum Red (Sigma). 50000 cells per sample were analyzed on a BD Facscalibur.

\section{Statistics}

The proteinuria data was analyzed with a $\chi^{2}$ test. Serum cytokines expressed by B6.TC mice treated with AAV-IL-10 or saline and age-matched B6 controls were compared with one-way ANOVA. All other data was analyzed with $t$-tests or Wilcoxon tests for unpaired data with continuity correction, 
depending whether the data was normally distributed or not. Statistical significance was obtained when $P \leq 0.05$ and is indicated in figures as ${ }^{*} P \leq 0.05,{ }^{* *} P \leq 0.01$ and ${ }^{* *} P \leq 0.001$.

\section{Results}

B6. TC Mice Produce More IL-10 than B6 Controls Due to a Greater Production from $\mathrm{CD4}^{+} \mathrm{T}^{-}$Cells and a Greater Number of perC B-1a Cells

We compared IL-10 production between B6.TC and B6 in various cell types. Anti-CD3 and anti-CD28 stimulated splenocytes produced significantly more IL-10 in B6.TC than in B6 controls (Figure 1a). Intracellular staining showed that a significantly greater proportion of B6.TC splenic CD4 ${ }^{+}$T cells produced IL-10 (Figure 1b). However, the amount of IL-10 produced by splenic B cells or bone-marrow-derived dendritic cells was similar between the two strains (data not shown). PerC B-1a cells, which constitute the major IL-10 producers, ${ }^{13}$ were analyzed separately. Whole peritoneal B6.TC cells produced significantly more IL-10 than B6 following LPS stimulation (Figure 1c). The peritoneal cavity of B6.TC mice contains, however, significantly more B1a cells, both in absolute number and percentage, than B6 controls. ${ }^{12}$ Intra-cellular staining showed that the percentage of B-1a cells producing IL-10 is actually equivalent between the 2 strains, with or without IgM or LPS stimulation (Figure 1d), indicating that the greater IL-10 production in the B6.TC peritoneal cavity results from the higher number of B-1a cells, but not from an enhanced production from individual cells. Unstimulated perC B-2 cells from B6.TC produced significantly more IL-10
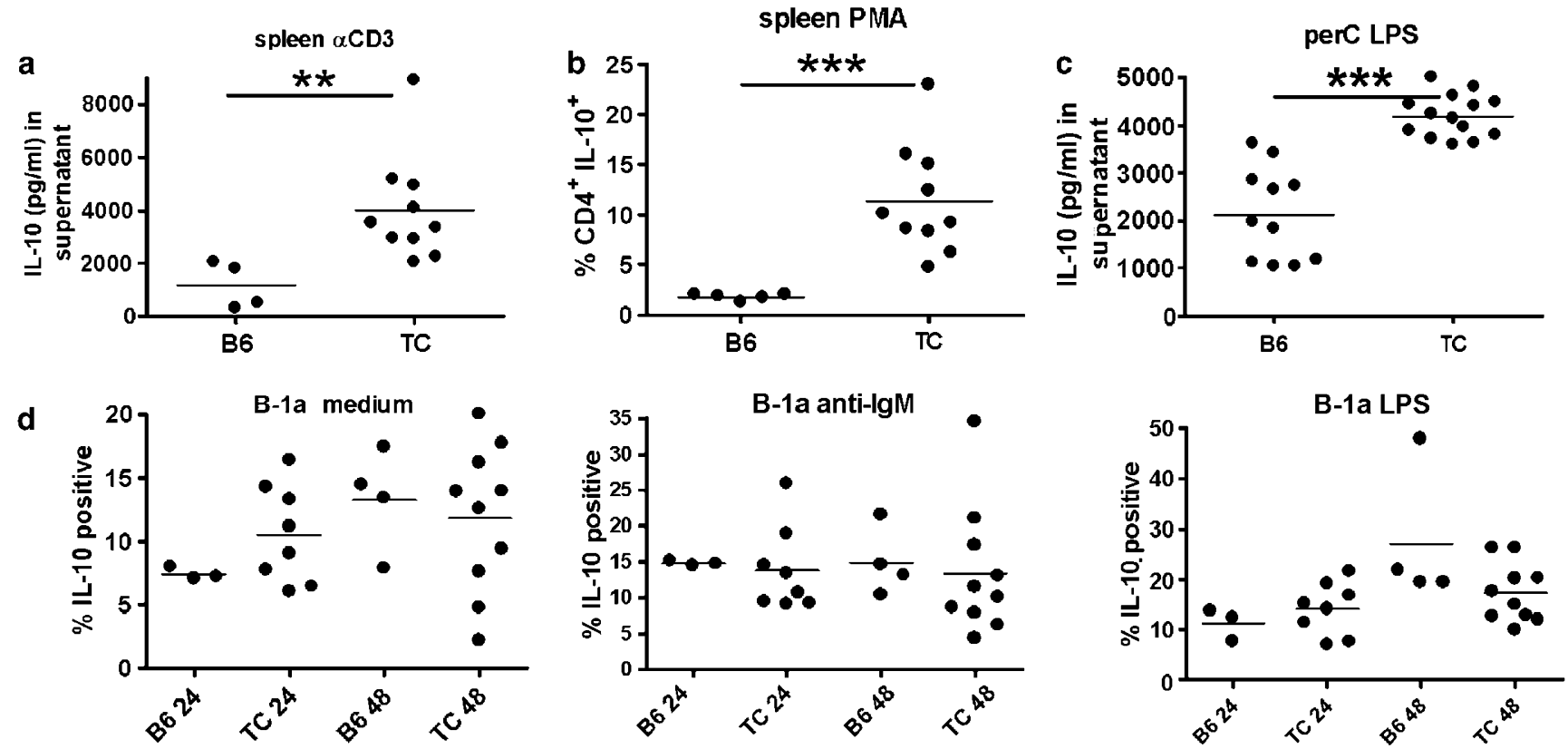

B-2 medium

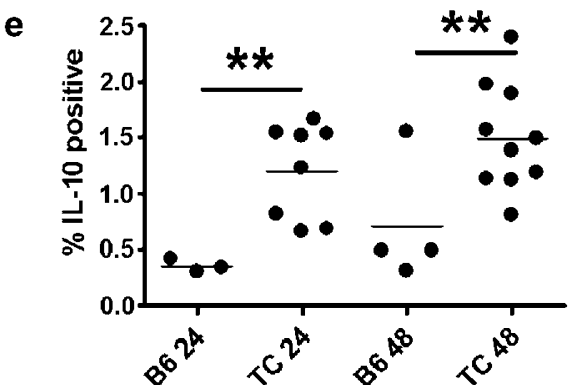

B-2 anti-lgM

B-2 LPS
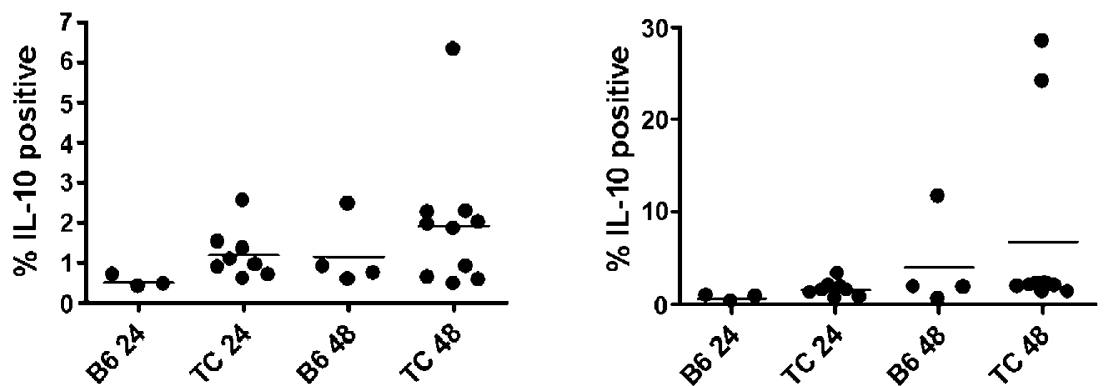

Figure 1 B6.TC mice produce more IL-10 than B6 controls. (a) Splenocytes were stimulated with anti-CD3 and anti-CD28 for 3d, and IL10 was measured in the supernatant by ELISA. (b) Splenocytes were stimulated with PMA and ionomycin for $5 \mathrm{~h}$, and intra-cellular IL-10 was measured in $\mathrm{CD}^{+}$cells gated by flow cytometry. (c) Total peritoneal cells were stimulated with $1 \mathrm{ug}$ LPS for $24 \mathrm{~h}$ and IL-10 was measured in the supernatant by ELISA. Peritoneal cells were stimulated were cultured in medium alone, anti-IgM $\mathrm{F}_{\mathrm{ab}(2)}$, or LPS, and intra-cellular IL-10 was measured in B-1 (d) and B-2 cells (e) after 24 or $48 \mathrm{~h}$ of stimulation as indicated on the $X$-axis for each strain. Significance levels are indicated for one-tailed $t$-tests. Each dot represents the value for an individual mouse. ${ }^{* *} P \leq 0.01$ and $* * * P \leq 0.001$. 
than B6, but the percentage of cells involved was minimal. Considering that the number of perC B-2 cells is reduced in B6.TC mice, ${ }^{12}$ this difference is unlikely to play a role in the overall IL-10 production.

\section{Overexpression of IL-10 by IL-10AAV Transduction Resulted in a Decreased Serum IgM and Anti-Nuclear IgG Production}

To analyze the effect of increased IL-10 levels in the B6.TC model, 6 weeks old B6.TC mice were transduced intramuscularly with $10^{10}$ IL-10 AAV serotype 1. Control mice were transduced with PBS alone. The animals were killed 26 weeks after transduction for analysis of auto-antibody production, immune cell distribution and activation, and renal pathology. IL-10 expression was detected in the muscle of transduced animals by RT-PCR 26 weeks after the injections, establishing the long-term and continuous expression of the cytokine from the AAV vector (Figure 2a). Previous work has shown that the AAV vector by itself does not induce IL-10 production, ${ }^{26}$ and as expected, no IL-10 was found in the muscle of mice injected with PBS alone. Two animals (\# 10 and 16) that did not show IL-10 expression at killing were excluded from analysis, as they could have been not transduced at all or with a lower dose of virus that provided only transient IL-10 expression. As previously shown with AAVIL-10, ${ }^{26}$ a moderate level of myositis was observed in transduced muscle of B6.TC mice (data not shown). In addition, we observed near the site of injection in one of the B6.TC mice severe focal neuritis and vasculitis (Figure 4a), confirming the potential local inflammation that may occur with AAV-IL-10 intramuscular transduction.

AAV-IL-10 transduction did not result in a detectable increased serum IL-10 (Figure 2b), confirming that the expression from the AAV vector corresponds to a very small amount of IL-10 as compared to injections of purified protein. Although inter-individual variation was high, the level of serum IL-10 was significantly higher in B6.TC mice (either AAV-IL-10 transduced or not) than in aged-matched unmanipulated B6 controls across a 6 weeks period (Figure $2 \mathrm{~b}$, one-way ANOVA $P<0.0096$ ), which corroborates the results reported earlier in this study. The functional effect of AAVIL-10 transduction was, however, detectable as a significant decrease in proinflammatory cytokines, IFN $\gamma 6$ weeks after transduction and $\mathrm{TNF} \alpha 4$ weeks after transduction (Figure 2b). Later on, these cytokines were expressed at similar levels between the two groups, suggesting that the functional effects of AAV-IL-10 expression were limited to 4-6 weeks after injection of the vectors.

AAV-IL-10 exposure significantly decreased total serum IgM ( $P=0.002$, Figure 3a) but had no effect of total IgG as shown at 18 weeks postinjection in Figure 3b. Total IgG2b, however, was significantly decreased in the AAV-IL-10 mice $(P=0.036$,
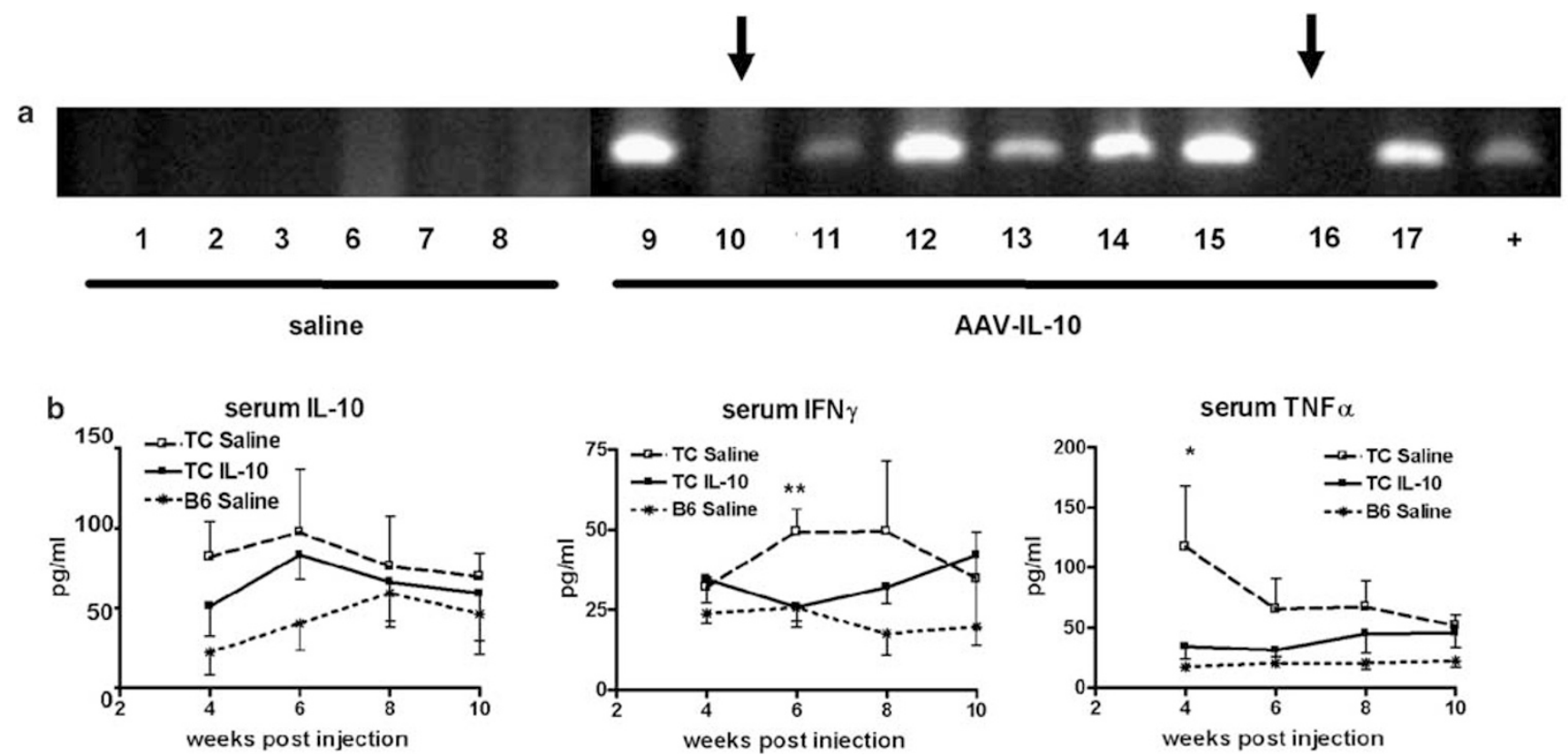

Figure 2 IL-10 expression in AAV-IL-10 transduced B6.TC mice. (a) Representative detection of IL-10 26 weeks after transduction. Nested RT-PCR was performed on the muscles injected either with saline (samples 1-8) or AAV-IL-10 (samples 9-17). ${ }^{+}$Indicates plasmid encoded AAV-IL-10 used as positive control. A negative control performed without cDNA showed no amplification product (data not shown). Arrows indicate samples in which AAV-IL-10 expression was not detected. (b) Comparison of serum IL-10, IFN $\gamma$ and TNF $\alpha$ in AAV-IL-10 transduced and saline-injected B6.TC mice and age-matched B6 controls (Mean and standard variations for 5 mice per group). Significance levels at individual time points were obtained with Wilcoxon tests. ${ }^{*} P \leq 0.05$ and ${ }^{* *} P \leq 0.01$. 

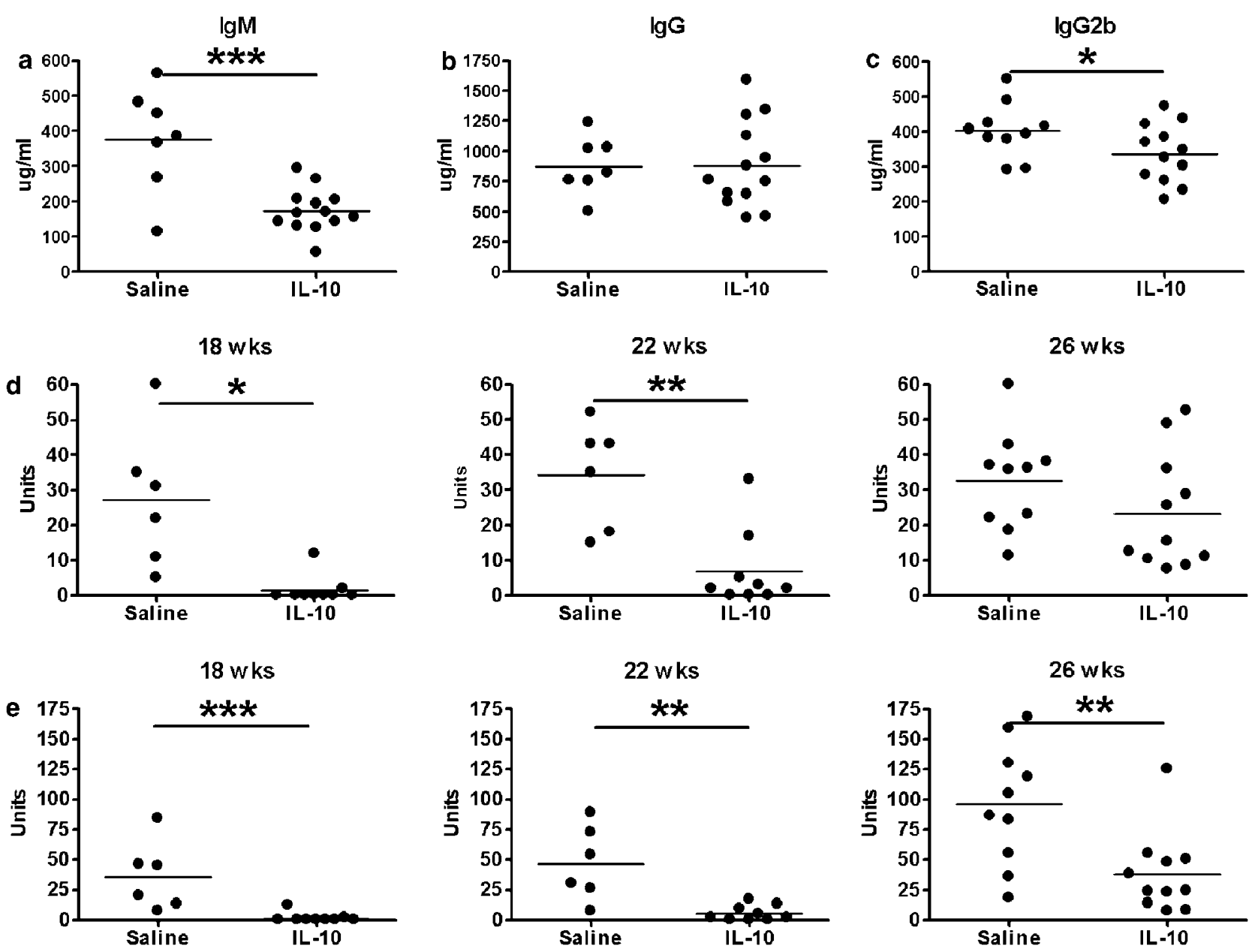

Figure 3 Effect of AAV-IL-10 on antibody production in B6.TC mice. AAV-IL10 resulted in significantly lower levels of total serum IgM (a) and IgG2b (c), but not total IgG (b), here shown at 18 weeks postinjection. Both anti-dsDNA (d) and antichromatin IgG (e) antibodies were also significantly reduced B6.TC transduced mice. Results are shown for 18, 22 and 26 weeks after AAV-IL-10 or saline injections. Anti-dsDNA IgG was not detected before 18 weeks postinjection and antichromatin IgG was not detected before 16 weeks postinjection, when it was similar to the results obtained at 18 weeks $(P<0.05$, data not shown). Significance levels are indicated for $t$-tests $(\mathbf{a}$ and $\mathbf{c})$ or Mann-Whitney tests (d and $\mathbf{e}$ ). Each dot represents the value for an individual mouse. ${ }^{*} P \leq 0.05,{ }^{* *} P \leq 0.01$ and ${ }^{* * *} P \leq 0.001$.

Figure 3c). The same results were obtained with sera obtained at 22 and 26 weeks postinjections (data not shown). Anti-dsDNA (Figure 3d) and antichromatin IgG (Figure 3e) production was significantly reduced in IL-10 transduced B6.TC mice, although it increased with age, and the difference was no longer significant for anti-dsDNA IgG 26 weeks postinjection.

\section{Overexpression of IL-10 by IL-10AAV Transduction Decreased Renal Disease}

IL-10 overexpression did not produce any significant histopathological change as compared to PBStreated controls. In particular, it was not associated with any histological changes in PAS-stained renal sections, and all AAV-IL-10 treated (Figure 4b) and control B6.TC mice presented global proliferative glomerulonephritis in more than $50 \%$ of there glomeruli. Excreting protein in the urine was, however, significantly decreased in AAV-IL-10 treated mice (Figure 5a), indicating a clinically less active renal pathology. Accordingly, a reduced amount of IgG and C3 deposits were found in the glomeruli of AAV-IL-10-treated mice as compared to controls (Figure 5b). The role of complement C3 and immune complex deposition in active lupus nephritis is well documented, and their reduction here corresponds with the reduced proteinuria. Overall, these results suggest that IL-10 overexpression reduced the severity, but did not eliminate lupus nephritis in B6.TC mice.

\section{IL-10 Overexpression Normalizes Plasma Cell Migration to the Bone Marrow and T-Cell Activation}

In order to understand the mechanisms by which IL10 overexpression affects autoimmune pathogenesis in B6.TC mice, we compared lymphocyte subset distribution and activation status in the bone 

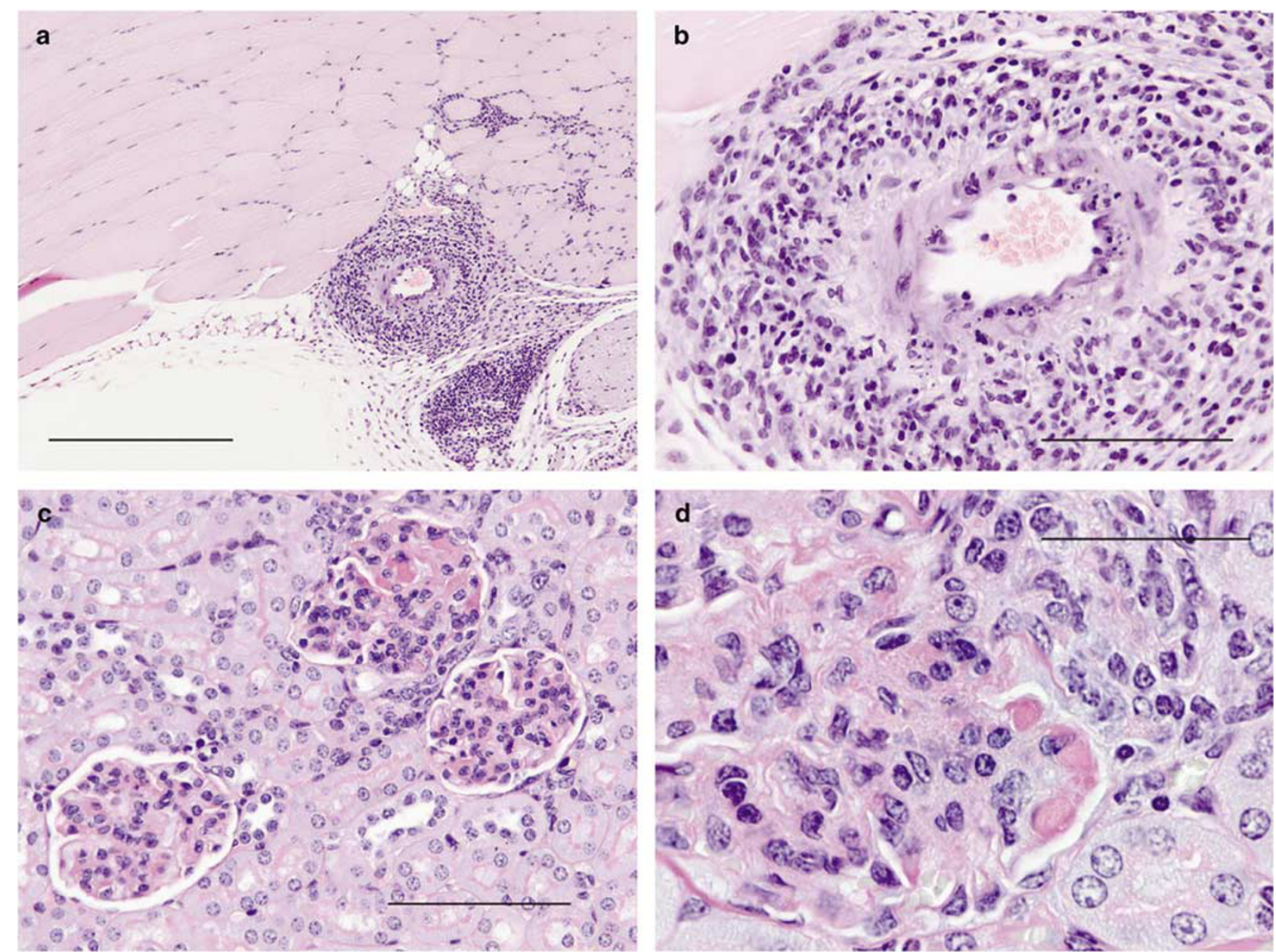

Figure 4 Representative histopathology of AAV-IL-10 transduced B6.TC mice. (a) This picture shows a portion of muscle with a portion of epimysial nerve (lower far left) and artery (mid-left) with extensive inflammation. Chronic inflammation extends through the perimysium and into the endomysium with fiber atrophy (scale $0.4 \mathrm{~mm}$ ). (b) This is a higher magnification of the artery showing acute inflammation of the intema, with few medial inflammatory cells and marked expansion of the adventitia (scale $0.1 \mathrm{~mm}$ ). (c) This is a view containing three glomeruli with global proliferative glomerulonephritis. One (upper center) shows capillary hyaline deposits. There is mild interstitial inflammation (scale $0.1 \mathrm{~mm}$ ) (d) Higher magnification of another glomerulus showing global hypercellularity, large capillary deposits (3 O'clock on glomerulus) and interstitial inflammation adjacent to the glomerulus (left) (scale $0.05 \mathrm{~mm}$ ).

marrow, spleen and peritoneal cavity. IL-10 overexpression increased the number of bone marrow CD24- ${ }^{-} D 43^{+}$lymphoid progenitors, but decreased the number of $\mathrm{CD} 24^{+} \mathrm{CD}^{+} 3^{+}$pro/early B cells (Figure 6a), suggesting that the cytokine affected early developmental events. No difference was found in the distribution of other B-cell subsets in the bone marrow, spleen or peritoneal cavity (data not shown), except for plasma cells. We have previously shown that plasma cells in B6.TC mice presented intrinsic defect in their ability to leave the spleen and lymph nodes to migrate to the bone marrow, ${ }^{36}$ which resulted in a high spleen/bone marrow plasma cell ratio. The number of syndecanpositive ${\mathrm{B} 220^{-}}^{-}$cells in the bone marrow was significantly higher in AAV-IL-10 treated mice, concomitant with a reduction of the number of splenic plasma cells, resulting in a significantly reduced spleen/bone marrow plasma cell ratio (Figure 6b).
IL-10 overexpression had a significant effect on T cells. The percentage CD44- ${ }^{-} \mathrm{CD} 62 \mathrm{~L}^{+}$naïve $\mathrm{CD} 4{ }^{+}$ $\mathrm{T}$ cells was increased while the number of $\mathrm{CD} 44^{+}$ $\mathrm{CD} 2 \mathrm{~L}^{-}$activated effector $\mathrm{CD}^{+} \mathrm{T}$ cells was decreased (Figure 7a). The reduction in T-cell activation was also manifested by a significantly reduced expression of the early activation marker CD69 (data not shown). The B6.TC mice are also characterized by an elevated CD4/CD8 ratio due to an impaired activation induced cell death (AICD) of the CD4 ${ }^{+}$ T-cells mapping to the Sle3 locus. ${ }^{37}$ We found that IL-10 overexpression normalized the CD4/CD8 ratio (Figure 7b), suggesting that it increased CD4 ${ }^{+} \mathrm{T}$ cell AICD. Finally, B6.TC mice have a reduced number of regulatory CD4 ${ }^{+} \mathrm{CD} 25^{+} \mathrm{CD} 2 \mathrm{~L}^{+} \mathrm{T}$ cells $\left(\mathrm{T}_{\text {Regs }}\right.$ ) that maps to the Sle1 locus. ${ }^{38}$ In addition of being a $\mathrm{T}_{\text {Regs }}$ marker, CD25 is also expressed on activated $\mathrm{T}$ cells, which are increased in B6.TC mice. We have therefore included CD62L marker in our measurement of $\mathrm{T}_{\text {Regs }}$ to circumvent this problem. 


\section{proteinuria}
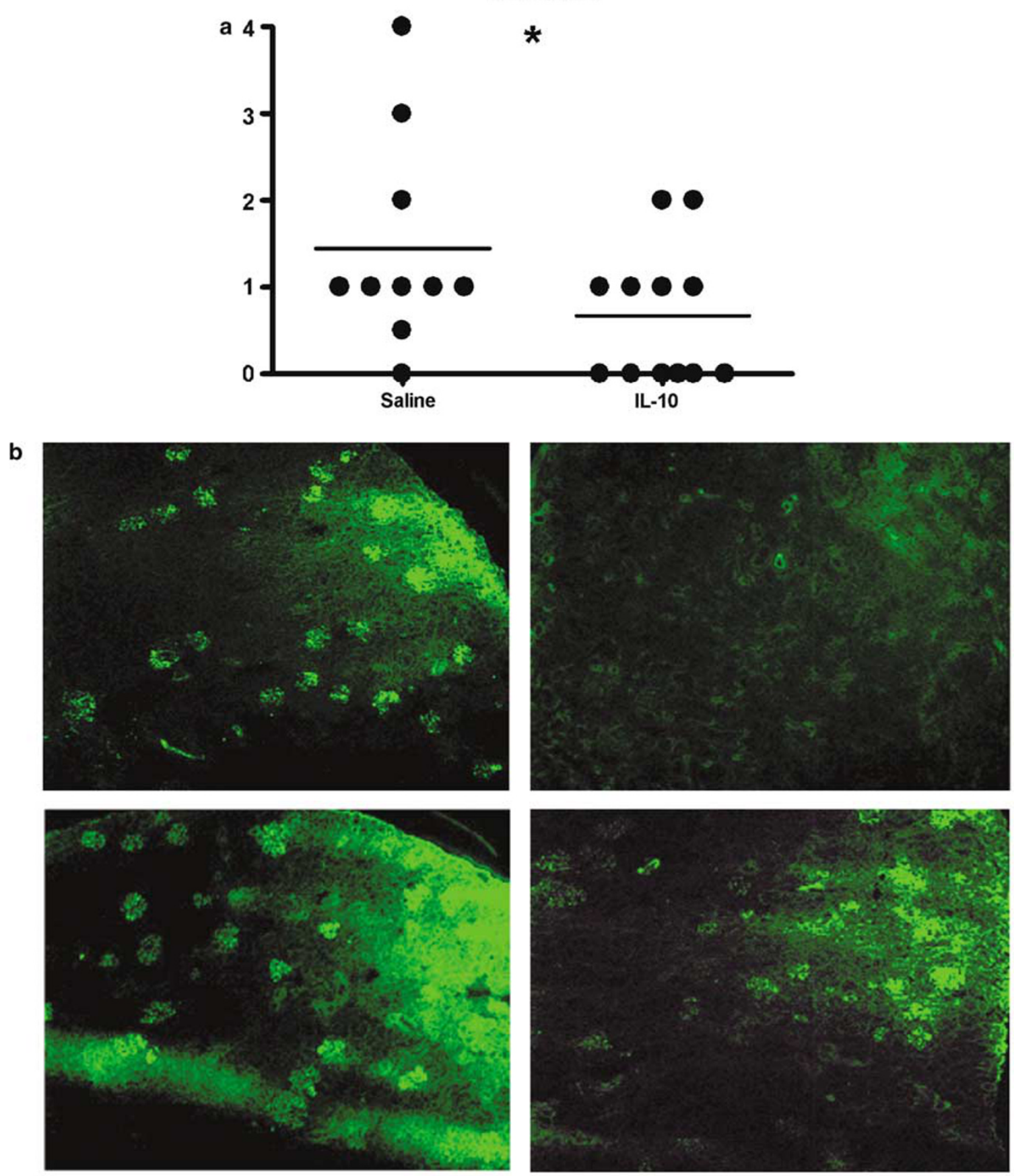

C3

\section{Saline}

IL-10

Figure 5 Effect of AAV-IL-10 on glomerulonephritis. (a) Proteinuria 26 weeks after AAV-IL-10 or saline injections. ${ }^{*} P \leq 0.05$. (b) Representative immunofluorescence stainings for IgG and C3 in saline or AAV-IL-10-treated mice. Magnification: $\times 50$.

Additional staining showed that the majority of these cells are CD69- ${ }^{-}$and express Foxp3 (data not shown). There was a trend in an increased percentage of splenic $\mathrm{T}_{\text {Regs }}$ in AAV-IL-10-transduced mice (Figure 7c), but it did not reach statistical significance $(P=0.09)$.

\section{Discussion}

Many studies have reported elevated levels of IL-10 in lupus patients and murine-prone strains. ${ }^{2,6}$ Transfer experiments have suggested that in SLE patients, IL-10 was produced by monocytes and 
$\mathrm{CD}^{2} 4^{-} \mathrm{CD}^{\circ} 3^{+} \mathrm{BM}$ progenitors

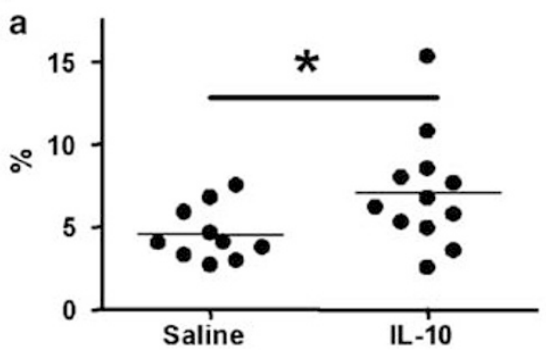

Saline

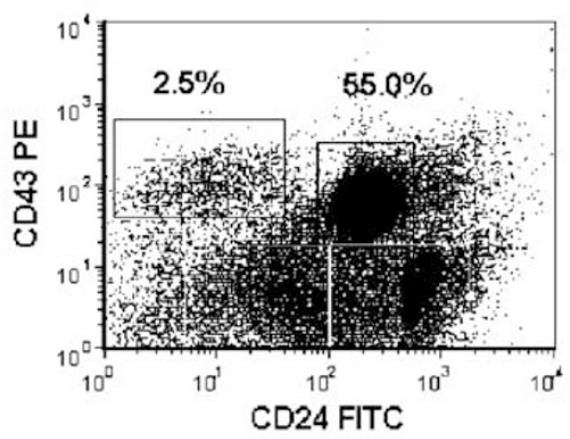

$\mathrm{BM} \mathrm{CD} 138^{+}$cells

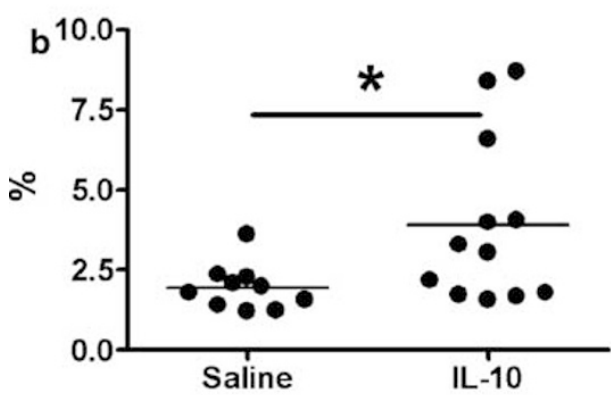

Saline

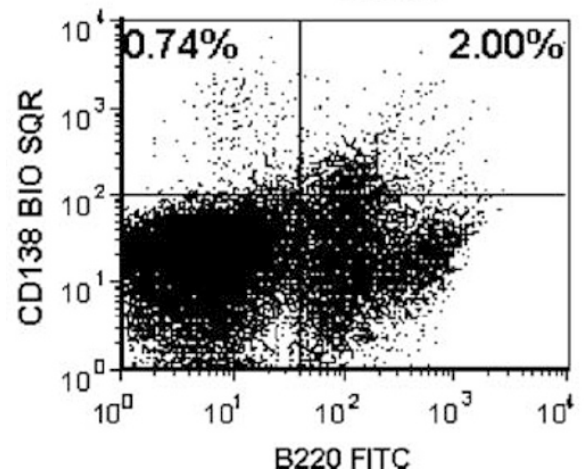

$\mathrm{CD} 24^{+} \mathrm{CD} 43^{+}$pro / early pre-B cells

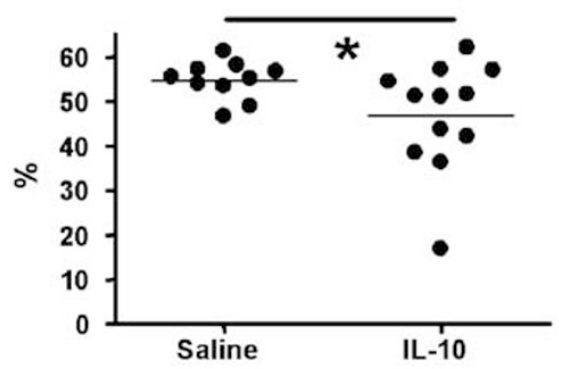

IL-10

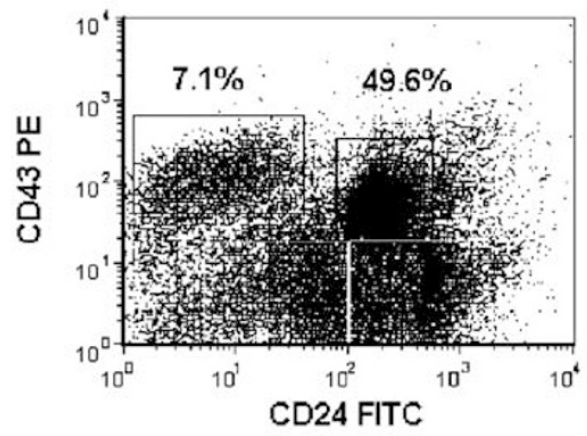

Spleen:BM plasma cells ratio

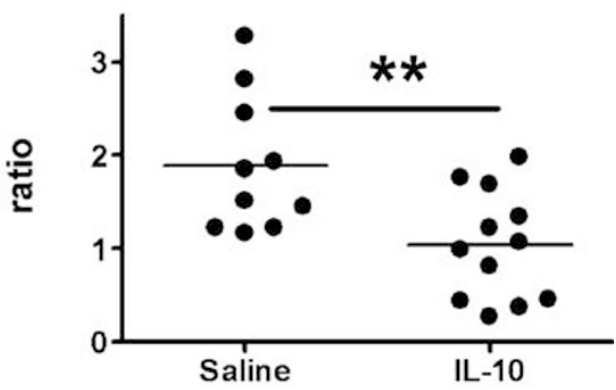

IL-10

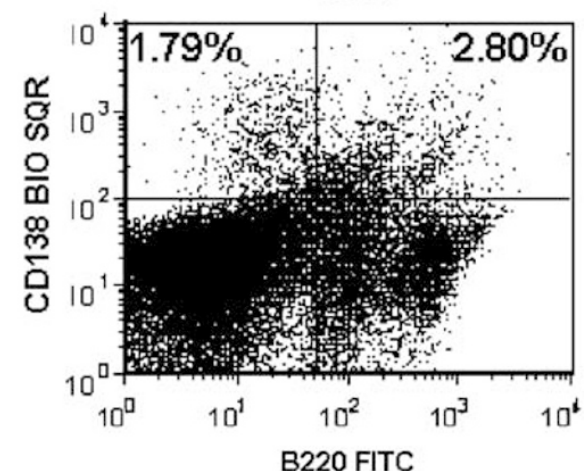

Figure 6 Effect of AAV-IL-10 on lymphocyte subset distribution in the bone marrow 26 weeks after transduction. (a) IL-10 overexpression affected early lymphocyte development, increasing the percentage of progenitor and decreasing the percentage of pro-B cells. (b) IL-10 overexpression increased the percentage of $\mathrm{B}_{22} 20^{-} \mathrm{CD}_{138^{+}}$plasma cells in the bone marrow and decreased their percentage in the spleen, resulting in a decreased spleen/bone marrow ratio. Representative FACS plots are shown for saline and IL-10AAV-treated mice. Statistical comparisons were performed with $t$-tests. Each dot represents the value for an individual mouse. ${ }^{*} P \leq 0.05$ and ${ }^{*} P \leq 0.01$. 

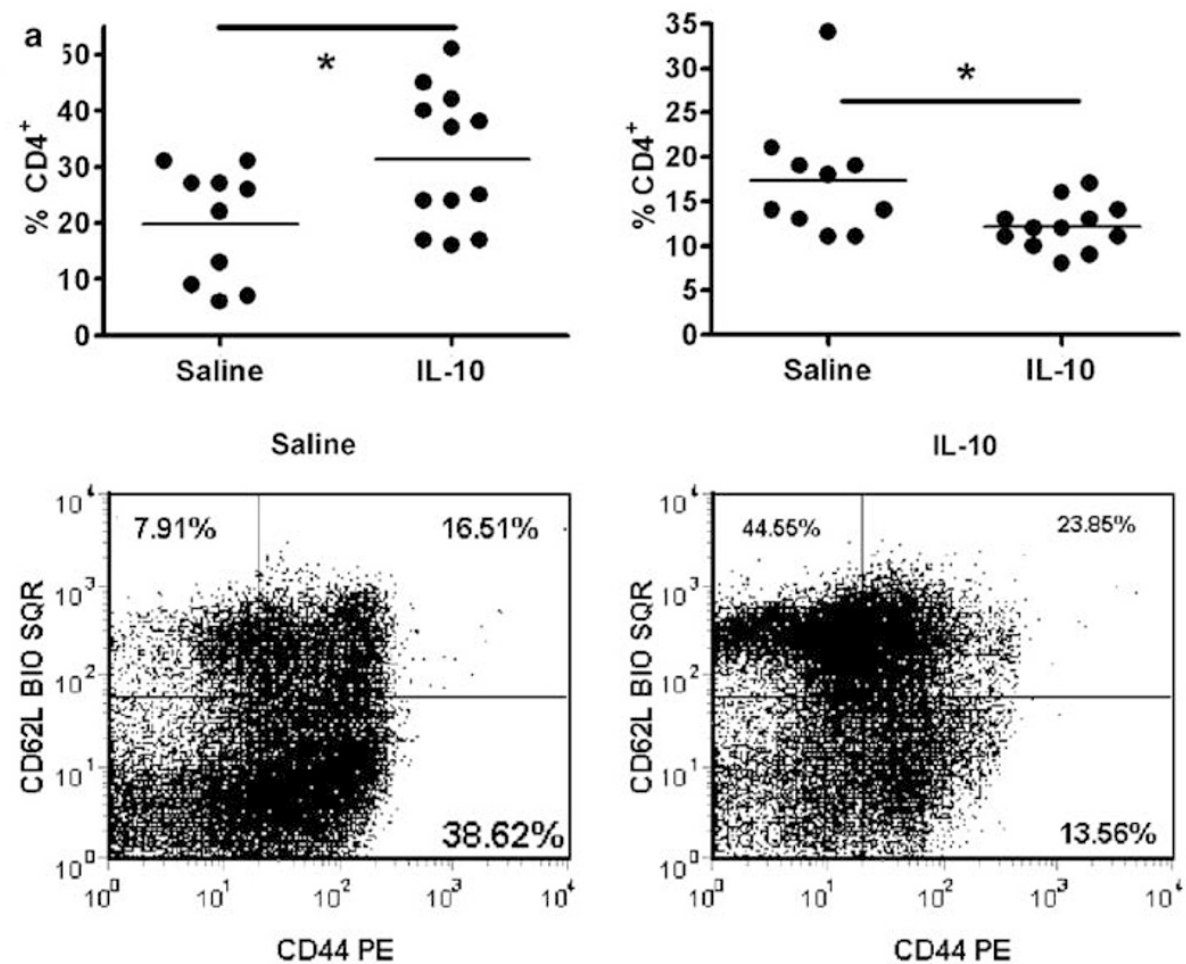

IL-10

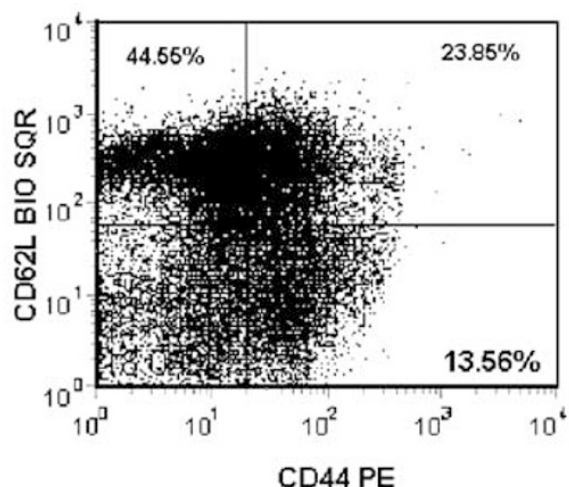

CD4/CD8

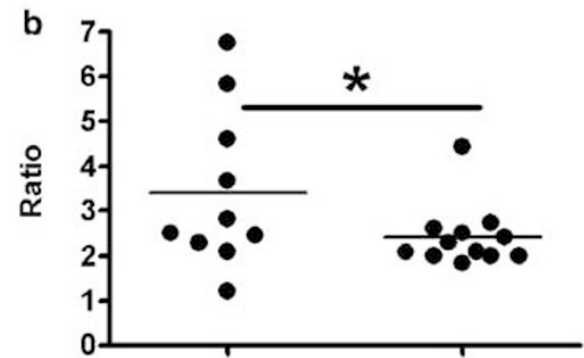

Saline

IL-10

Saline

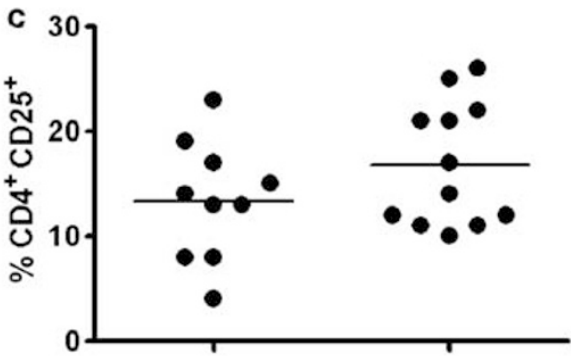

Saline

IL-10
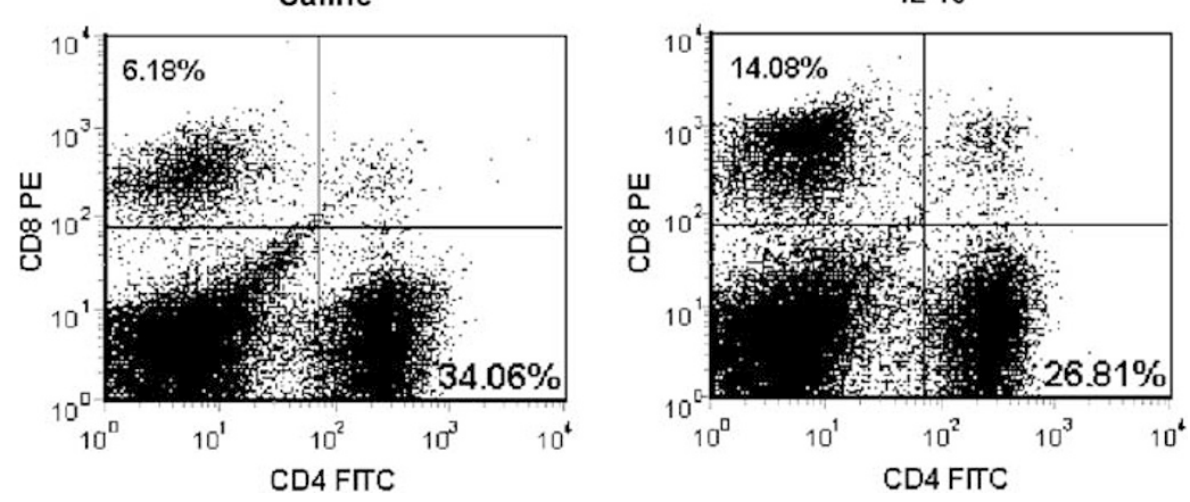

Figure 7 Effect of AAV-IL-10 on splenic T cells 26 weeks after transduction. (a) CD4 ${ }^{+}$activation levels as measured with CD44 and CD62L expression. (b) CD4/CD8 ratio. (c) $\mathrm{T}_{\text {Regs }}$ expressed as the percentage CD4 ${ }^{+}$CD25 ${ }^{+}$cells that express CD62L. Representative FACS plots are shown for saline and IL-10AAV-treated mice. Statistical comparisons were performed with $t$-tests. Each dot represents the value for an individual mouse. ${ }^{*} P \leq 0.05$. 
autoreactive B cells, but not T cells. ${ }^{39}$ In mice, it is not clear what is the source of the elevated IL-10 production. Marginal zone B cells in some lupusprone strains are hyper responsive to TLR9 stimulation, which results in abundant IL-10 secretion. ${ }^{41}$ This IL-10 production suppresses splenocyte production of IL-12, and it has been suggested that this regulatory activity of $\mathrm{B}$ cells may contribute to lupus pathogenesis. ${ }^{40-42}$ In the NZM2410 model, including B6.TC, the marginal zone B cell compartment is significantly reduced (Morel et al, in preparation), which does not fit the previous model, and we have not observed an increased IL-10 production in these cells (data not shown). B-1a cells, which are the main producers of IL-10 in the mouse, ${ }^{13}$ are found in high numbers in the lupus prone strains $\mathrm{NZB}^{43}$ NZB/W F1, NZM2410, ${ }^{44}$ and B6.TC. ${ }^{12}$ Whether this expanded cell compartment was the cause for the high IL-10 level has, however, never been directly addressed. We found that, on a per cell basis, IL-10 production was similar between B6.TC and control B6 mice for all cell types, except $\mathrm{CD} 4^{+} \mathrm{T}$ cells. NZM2410 T cells produce high levels of IL-4, ${ }^{31}$ but this dual over production of IL-10 and IL-4 in the NZM2410 model is unlikely to correspond to a bias toward a $\mathrm{T}_{\mathrm{H} 2}$ cytokine profile. We have indeed shown that Sle1, the only genetic locus that directly affects T-cell phenotypes in this model, is associated with an over production of IL-2, IFN $\gamma$ and IL- $4,{ }^{38}$ and this phenotype, which reflect a generalized hyperactivation of the T-cell effector functions, is maintained in B6.TC mice. ${ }^{45}$ The lack of overexpression by other cell types supports a different regulatory mechanism in T cells, as previously postulated. ${ }^{14}$ It was of special interest that B6.TC B-1a cells produced normal levels of IL-10, whether stimulated or not, suggesting that the genes from the lupus-prone mouse affect the number of B-1a cells, but do not impact on their functions. Nonetheless, B6.TC mice overall produce more IL-10 due to the cumulative effects of their large number of B-1a cells and the increased output from $\mathrm{CD}^{+}{ }^{+} \mathrm{T}$ cells. These results also indicate that the lupus-associated increase in IL-10 production is complex and may result from multiple processes, such as here in our model, an increase in the number of cells that are major producers, and an increase in the intrinsic capacity of other cells, here CD4 ${ }^{+}$T cells, to produce that cytokine. The involvement of various cell types may vary between lupus models and among lupus patients, which may contribute to the different results obtained with the manipulations of IL-10 levels.

Given the high level of IL-10 in B6.TC mice, it could have been predicted that increasing this cytokine expression would further promote disease development. We elected to use an AAV vector to express IL-10. This construct has shown efficacy in multiple disease models in which it was successfully used as an anti-inflammatory gene therapy approach. ${ }^{18-30}$ Mice were treated at 6 weeks of age, which is very early in the development of the autoimmune process in this model in which sustained levels of anti-dsDNA IgG antibodies appear between 4 and 5 months of age. ${ }^{11}$ The experiment was terminated at 7 months of age, which corresponds to a phase of active autoimmunity, but before terminal end stage disease for most mice. ${ }^{11}$ We were able to show active IL-10 expression in the AAV-transduced muscle at the time of sacrifice, indicating a sustained expression throughout the experiment.

IL-10 overexpression significantly reduced the production of anti-dsDNA and antichromatin IgG antibodies at 18 and 22 weeks post-transduction, and the difference was no longer significant at 26 weeks of age for anti-dsDNA IgG. This result indicates that IL-10 overexpression resulted in a significant delay rather than in a complete inhibition of auto-antibody production. Antinuclear autoantibodies are the hall-mark of lupus, and therefore their significant reduction in AAV-IL-10-treated mice clearly indicates that IL-10 overexpression globally reduced and delayed the induction of systemic autoimmunity. Another hallmark of lupus in murine models is immune complex mediated glomerulonephritis. Although glomerulonephritis scores were similar between treated and control B6.TC mice, AAV-IL-10 significantly reduced proteinuria, immune-complex deposition, and mesangial proliferation, all of which are markers of active clinical disease. The fact that protection was not complete can be linked at least partially to the break in tolerance to nuclear antigens that we observed toward the end of the treatment period. The effect of AAV-IL-10 expression was transient, considering either the downregulation of inflammatory cytokines or auto-antibodies. This by itself could be due to either the limited life-span for the production of IL-10 by the AAV vectors, or to this production being overcome with time with an expanding autoimmune process. Precise time-course analyses will be required to distinguish these two possibilities. In addition, non-anti-dsDNA auto-antibodies directed to yet undefined specificities play a significant role in pathogenesis in the NZM model, ${ }^{46}$ and the generation of these auto-antibodies may be less affected by IL-10.

We investigated the mechanisms by which IL-10 overexpression reduced the autoimmune pathogenesis in the B6.TC mice. Serum IgM level were significantly decreased in AAV-IL-10-treated mice, which was unexpected given the effects of IL-10 on B-cell survival, differentiation and proliferation. ${ }^{47,48}$ In our model, AAV-IL-10 did not increase the number or subset distribution of $B$ cells either in the spleen or the peritoneal cavity, including the B1a subset, which is largely responsible for serum IgM production. These results suggest that the level of IL-10 expression provided by the AAV vector was below the level required for a proliferative effect on $\mathrm{B}$ cells. The role of $\mathrm{IL}-10$ on immunoglobulin 
production is less clear, as serum immunoglobulin levels are normal in IL-10 deficient mice. ${ }^{49}$ Serum IgM levels were decreased in AAV-IL-10-treated B6.TC mice, demonstrating that in this model, terminal differentiation of autoreactive B-1 cells is not enhanced by IL-10, as it has been suggested in a transgenic model of antierythrocyte antibodies. ${ }^{50} \mathrm{We}$ did not find any difference in IgG levels, or IgG isotypes, except a modest difference for IgGb levels. Notably, we did not find a difference in the IgG1/ IgG2a ratio, which argues against IL-10 exerting its effect through a $\mathrm{T}_{\mathrm{H} 1} / \mathrm{T}_{\mathrm{H} 2}$ skewing. Interestingly, we found that IL-10 overexpression restored B6.TC plasma cells migration to the bone marrow. The accumulation of splenic plasma cells is a characteristic of the NZM2410 model that is intrinsic to bone marrow-derived leukocytes. ${ }^{37}$ The results presented in this study demonstrate that an excess of IL-10 exposure can reverse this defect, and suggest that it plays a role in pathogenesis as its normalization is associated with a decreased auto-antibody production and kidney disease.

IL-10 immuno-regulatory effects on $\mathrm{T}$ cells have been well documented (reviewed by Mocellin et $a l^{1}$ ). Our results showed that AAV-IL-10 significantly reduced $\mathrm{CD}^{+}{ }^{+}$T-cell activation in B6.TC mice. It also significantly reduced the CD4/CD8 ratio, implying that it normalized $\mathrm{CD} 4^{+} \mathrm{T}$ cell AICD. The AICD impairment in B6.TC mice was shown recently to be mediated by Sle3-expressing DCs that have a proinflammatory cytokine profile. ${ }^{51}$ Our results suggest that IL-10 exposure restores Sle3expressing DCs to mediate AICD. It also strongly suggests that $\mathrm{CD} 4{ }^{+}$T-cells activation and impaired AICD play a significant role in lupus pathogenesis in our model.

Finally, we have previously shown that AAV-IL-10 prevention of type 1 diabetes in the NOD mouse was mediated by $\mathrm{CD} 4{ }^{+} \mathrm{CD} 25^{+} \mathrm{T}_{\text {Reg. }}{ }^{30} \mathrm{AAV}$-IL-10 tended to increase the number of $\mathrm{T}_{\mathrm{Reg}}$ in B6.TC mice, but that effect was not significant. This could be interpreted as AAV-IL-10 had a significant effect on $\mathrm{T}_{\mathrm{Reg}}$ numbers, but as in the case for anti-dsDNA auto-antibody, it was no longer significant at the end of the experiment. It could also indicate that AAV-IL-10 engaged another type of regulatory $\mathrm{T}$ cells, known as $\mathrm{T}_{\mathrm{R} 1} \cdot \mathrm{T}_{\mathrm{R} 1}$ cells secrete high amounts of IL-10 and TGF $\beta$, and they can be can be induced by IL-10 exposed DCs, ${ }^{52}$ establishing a regulatory loop between these to cell types through IL-10. ${ }^{1}$ Further studies will be necessary to determine which of these regulatory subsets is mobilized by AAV-IL-10 in the B6.TC model.

In conclusion, our data showed that although B6.TC mice produce higher IL-10 levels that nonautoimmune control mice, an overexpression of IL-10 decreased T-cell activation, auto-antibody production and autoimmune pathogenesis. These results reinforce the notion that IL-10 exerts multiple functions and commend caution in equating high levels of IL-10 and increased pathogenesis in systemic autoimmunity.

\section{Acknowledgements}

We thank Jessica Lohman for technical assistance, and Drs James Crawford, Minoru Satoh, Michael Clare-Salzler, and Margaret Wallace for helpful suggestions.

Funding: NIH RO1 AI-058150 to LM.

\section{References}

1 Mocellin S, Marincola F, Rossi CR, et al. The multifaceted relationship between IL-10 and adaptive immunity: putting together the pieces of a puzzle. Cytokine Growth Factor Rev 2004;15:61-76.

2 Hagiwara E, Gourley MF, Lee S, et al. Disease severity in patients with systemic lupus erythematosus correlates with an increased ratio of interleukin-10:Interferon-gamma-secreting cells in the peripheral blood. Arthritis Rheum 1996;39:379-385.

3 Alarcon-Riquelme ME, Lindqvist $\mathrm{AKB}$, Jonasson I, et al. Genetic analysis of the contribution of IL10 to systemic lupus erythematosus. J Rheumatol 1999;26: 2148-2152.

4 Grondal G, Kristjansdottir H, Gunnlaugsdottir B, et al. Increased number of interleukin-10-producing cells in systemic lupus erythematosus patients and their firstdegree relatives and spouses in Icelandic multicase families. Arthr Rheumat 1999;42:1649-1654.

5 Gibson AW, Edberg JC, Wu J, et al. Novel single nucleotide polymorphisms in the distal IL-10 promoter affect IL-10 production and enhance the risk of systemic lupus erythematosus. J Immunol 2001;166:3915-3922.

6 Mageed RA, Prud'homme GJ. Immunopathology and the gene therapy of lupus. Gene Therapy 2003;10:861-874.

7 Ishida H, Muchamuel T, Sakaguchi S, et al. Continuous administration of anti-interleukin 10 antibodies delays onset of autoimmunity in NZB/W F1 mice. J Exp Med 1994;179:305-310.

8 Yin ZN, Bahtiyar G, Zhang N, et al. IL-10 regulates murine lupus. J Immunol 2002;169:2148-2155.

9 Rudofsky UH, Evans BD, Balaban SL, et al. Differences in expression of lupus nephritis in New-Zealand mixed $\mathrm{H}-2(\mathrm{Z})$ homozygous inbred strains of mice derived from New-Zealand black and New-Zealand white mice-origins and initial characterization. Lab Invest 1993;68:419-426.

10 Morel L, Rudofsky UH, Longmate JA, et al. Polygenic control of susceptibility to murine systemic lupus erythematosus. Immunity 1994;1:219-229.

11 Morel L, Croker BP, Blenman KR, et al. Genetic reconstitution of systemic lupus erythematosus immunopathology with polycongenic murine strains. Proc Natl Acad Sci USA 2000;97:6670-6675.

$12 \mathrm{Xu}$ Z, Duan B, Croker BP, et al. Genetic dissection of the murine lupus susceptibility locus Sle2: contributions to increased peritoneal B-1a cells and lupus nephritis map to different loci. J Immunol 2005;175:936-943.

13 O'Garra A, Chang R, Go N, et al. Ly-1 B (B-1) cells are the main source of B cell-derived interleukin 10. Eur J Immunol 1992;22:711-717.

14 Moore KW, Waal-Malefyt R, Coffman RL, et al. Interleukin-10 and the interleukin-10 receptor. Ann Rev Immunol 2001;19:683-765.

15 Rabinowitz JE, Samulski J. Adeno-associated virus expression systems for gene transfer. Curr Opin Biotech 1998;9:470-475. 
16 Kessler PD, Podsakoff GM, Chen XI, et al. Gene delivery to skeletal muscle results in sustained expression and systemic delivery of a therapeutic protein. Proc Natl Acad Sci USA 1996;93:14082-14087.

17 Flotte TR. Adeno-Associated Virus-based gene therapy for inherited disorders. Pediatr Res 2005;58:1143-1147.

18 Yamano S, Scott DE, Huang LY, et al. Protection from experimental endotoxemia by a recombinant adenoassociated virus encoding interleukin 10. J Gene Med 2001;3:450-457.

19 Apparailly F, Millet V, Noel D, et al. Tetracyclineinducible interleukin-10 gene transfer mediated by an adeno-associated virus: application to experimental arthritis. Hum Gene Ther 2002;13:1179-1188.

20 Jennings K, Miyamae T, Traister R, et al. Proteasome inhibition enhances AAV-mediated transgene expression in human synoviocytes in vitro and in vivo. Mol Ther 2005;11:600-607.

21 Yoshioka T, Okada T, Maeda Y, et al. Adeno-associated virus vector-mediated interleukin-10 gene transfer inhibits atherosclerosis in apolipoprotein E-deficient mice. Gene Therapy 2004;11:1772-1779.

22 Watanabe M, Kashiwakura Y, Kusumi N, et al. Adenoassociated virus-mediated human IL-10 gene transfer suppresses the development of experimental autoimmune orchitis. Gene Therapy 2005;12:1126-1132.

23 Broderick CA, Smith AJ, Balaggan KS, et al. Local administration of an adeno-associated viral vector expressing IL-10 reduces monocyte infiltration and subsequent photoreceptor damage during experimental autoimmune uveitis. Mol Ther 2005;12:369-373.

24 Smith JR, Verwaerde C, Rolling F, et al. Tetracyclineinducible viral interleukin-10 intraocular gene transfer, using adeno-associated virus in experimental autoimmune uveoretinitis. Hum Gene Ther 2005;16:1037-1046.

$25 \mathrm{Mu}$ W, Ouyang X, Agarwal A, et al. IL-10 suppresses chemokines, inflammation, and fibrosis in a model of chronic renal disease. J Am Soc Nephrol 2005;16: 3651-3660.

26 Goudy K, Song SH, Wasserfall C, et al. Adenoassociated virus vector-mediated IL-10 gene delivery prevents type 1 diabetes in NOD mice. Proc Natl Acad Sci USA 2001;98:13913-13918.

27 Zhang YC, Pileggi A, Agarwal A, et al. Adenoassociated virus-mediated IL-10 gene therapy inhibits diabetes recurrence in syngeneic islet cell transplantation of NOD mice. Diabetes 2003;52:708-716.

28 Yang Z, Chen M, Wu R, et al. Suppression of autoimmune diabetes by viral IL-10 gene transfer. J Immunol 2002;168:6479-6485.

29 Carter JD, Chen M, Ellett JD, et al. Impact of donor immune cells in pancreatic islet transplantation. Transpl Proc 2004;36:2866-2868.

30 Goudy KS, Burkhardt BR, Wasserfall C, et al. Systemic overexpression of IL-10 induces CD4(+)CD25(+) cell populations in vivo and ameliorates type 1 diabetes in nonobese diabetic mice in a dose-dependent fashion. J Immunol 2003;171:2270-2278.

31 Singh RR, Saxena V, Zang S, et al. Differential contribution of IL-4 and STAT6 vs STAT4 to the development of lupus nephritis. J Immunol 2003;170:4818-4825.

32 Xia CQ, Kao KJ. Induction of immune tolerance across major histocompatibility complex barrier by transfusion of ultraviolet B-irradiated immature dendritic cells. Transfusion 2005;45:181-188.

33 Hauswirth WW, Lewin AS, Zolotukhin S, et al. Production and purification of recombinant adeno-associated virus. Methods Enzymol 2000;316: 743-761.

34 Weening JJ, D'Agati VD, Schwartz MM, et al. The classification of glomerulonephritis in systemic lupus erythematosus revisited. J Am Soc Nephrol 2004;15: 241-250.

35 Quigg RJ. Complement and autoimmune glomerular diseases. Curr Dir Autoimm 2004;7:165-180.

36 Erickson LD, Lin LL, Duan B, et al. A genetic lesion that arrests plasma cell homing to the bone marrow. Proc Natl Acad Sci USA 2003;100:12905-12910.

37 Mohan C, Yu Y, Morel L, et al. Genetic dissection of Sle pathogenesis: Sle3 on murine chromosome 7 impacts $\mathrm{T}$ cell activation, differentiation, and cell death. J Immunol 1999;162:6492-6502.

38 Chen Y, Cuda C, Morel L. Genetic determination of T cell help in loss of tolerance to nuclear antigens. J Immunol 2005;174:7692-7702.

39 Emilie D, Zou W, Fior R, et al. Production and roles of IL-6, IL-10, and IL-13 in B-lymphocyte malignancies and in B-lymphocyte hyperactivity of HIV infection and autoimmunity. Methods 1997;11:133-142.

40 Brummel R, Lenert P. Activation of marginal zone B cells from lupus mice with type A(D) CpG-oligodeoxynucleotides. J Immunol 2005;174:2429-2434.

41 Lenert P, Brummel R, Field EH, et al. TLR-9 activation of marginal zone B Cells in lupus mice regulates immunity through increased IL-10 production. J Clin Immunol 2005;25:29-40.

42 Mizoguchi A, Bhan AK. A case for regulatory B cells. J Immunol 2006;176:705-710.

43 Hayakawa K, Hardy RR, Herzenberg LA. Peritoneal Ly-1 B-Cells-Genetic-Control, Autoantibody Production, Increased Lambda Light Chain Expression. Eur J Immunol 1986;16:450-456.

44 Mohan C, Morel L, Yang P, et al. Accumulation of splenic B1a cells with potent antigen-presenting capability in NZM2410 lupus-prone mice. Arthr Rheumat 1998;41:1652-1662.

$45 \mathrm{Xu}$ Z, Duan B, Croker BP, et al. STAT4 deficiency reduces autoantibody production and glomerulonephritis in a mouse model of lupus. Clin Immunol 2006;120:189-198.

46 Waters ST, McDuffie M, Bagavant H, et al. Breaking tolerance to double stranded DNA, nucleosome, and other nuclear antigens is not required for the pathogenesis of lupus glomerulonephritis. J Exp Med 2004;199:255-264.

47 Rousset F, Garcia E, Defrance T, et al. Interleukin-10 is a potent growth and differentiation factor for activated human lymphocytes-B. Proc Natl Acad Sci USA 1992;89:1890-1893.

48 Levy Y, Brouet JC. Interleukin-10 prevents spontaneous death of germinal center B-cells by induction of the Bcl-2 protein. J Clin Invest 1994;93:424-428.

49 Kuhn R, Lohler J, Rennick D, et al. Interleukin-10deficient mice develop chronic enterocolitis. Cell 1993;75:263-274.

50 Watanabe N, Ikuta K, Nisitani S, et al. Activation and differentiation of autoreactive B-1 cells by interleukin 10 induce autoimmune hemolytic anemia in Fasdeficient antierythrocyte immunoglobulin transgenic mice. J Exp Med 2002;196:141-146.

51 Zhu JK, Liu XB, Xie C, et al. T cell hyperactivity in lupus as a consequence of hyperstimulatory antigenpresenting cells. J Clin Invest 2005;115:1869-1878.

52 Roncarolo MG, Bacchetta R, Bordignon C, et al. Type 1 T regulatory cells. Immunol Rev 2001;182:68-79. 